\title{
Physical and chemical properties of the tsunami sediment deposited by the Great East Japan Earthquake
}

\author{
Y.KAWABE ${ }^{1 *}$, K.MIYAZAKI ${ }^{1}$, J.HARA ${ }^{1}$, AND \\ T.KOMAI ${ }^{2}$ \\ ${ }^{1}$ National Institute of Advanced Industrial Science and \\ Technology, Tsukuba 305-8567, Japan (*correspondence: \\ y-kawabe@aist.go.jp) \\ ${ }^{2}$ Tohoku university, Sendai 980-8579, Japan
}

\section{Introduction}

The tsunami caused by the Great East Japan Earthquake of March 11, 2011, deposited a lot of submarine deposit as tsunami deposit on farmland or urban areas. These tsunami deposits contain toxic heavy metals such as arsenic or lead which affect human health. In this study, the physical/ chemical properties of tsunami deposits caused by the Great East Japan Earthquake were investigated.

\section{Methods}

Tsunami deposits were sampled from the coastline of the eastern region of Japan (Aomori, Iwate, Miyagi, Fukushima, Ibaraki and Chiba prefecture). A particle size distribution was measured by a laser diffraction particle size analyzer, and the quantity of organic component was determined by the ignition loss. The heavy metals containing in the tsunami deposits and leaching values from them were conducted by the methods for Japanese Soil Contamination Countermeasures Act.

\section{Results and Discussions}

The particle size distribution of the tsunami deposits varied with the sampling point. Those sampled from Aomori and southern Fukushima to Chiba coastline was mainly sand, while those sampled from Iwate to northern Fukushima coastline contained a lot of silt or clay. A higher organic component, and leaching value of arsenic, lead and fluorine were observed in the silty or clayey rich tsunami sediment, which indicate that the submarine sediments from Iwate to the northern Fukushima might contain a lot of these heavy metals. There were some sites in excess of Japanese criteria for the leaching values of these heavy metals, although almost all of heavy metals in the tsunami deposits were within the Japanese criteria. 